\title{
Cytogenetic and Embryologic Analyses of the Mechanism of Parthenogenesis Induced by 1BL/1RS Male Sterile Lines in Wheat
}

\author{
N. NiU ${ }^{1 *}$, Y.L. SonG ${ }^{1 *}$, F. WeI ${ }^{1}$, H.M. LIU ${ }^{1}$, S.M. MA ${ }^{1}$, H.Y. ZHAO ${ }^{2}$ and G.S. ZHANG ${ }^{1 * *}$ \\ ${ }^{1}$ College of Agronomy, Northwest A\& F University / National Yangling Agricultural \\ Biotechnology \& Breeding Centre / Yangling Branch of State Wheat Improvement Centre / \\ Wheat Breeding Engineering Research Centre, Ministry of Education / Key Laboratory of Crop Heterosis \\ of Shaanxi Province, Yangling, 712100, Shaanxi, China \\ ${ }^{2}$ College of Plant Protection, Northwest A\& F University, Yangling, 712100, Shaanxi, China \\ (Received 16 April 2015; Accepted 7 October 2015; \\ Communicated by H. Grausgruber)
}

\begin{abstract}
In this study, we employed electron microscopy to investigate the cytogenetic and embryologic mechanisms of parthenogenesis induced in the 1BL/1RS male sterile lines of wheat. Analysis of the root tips and acid polyacrylamide gel electrophoresis indicated that all of the male sterile lines and their maintainer lines were 1BL/1RS translocation lines, whereas the restorer lines were non-1BL/1RS translocation lines. Furthermore, the chromosomes of 1BL/1RS wheat lines with T. aestivum cytoplasm and Aegilops cytoplasm (include Ae. kotschyi, Ae. ventricosa, Ae. variabilis) paired abnormally at different rates during meiotic metaphase I (MMI). The translocated segment size of the 1RS chromosome and the specific nuclear-alloplasm interaction impaired the pairing of homologous chromosome in the background of the specific Aegilops cytoplasm at MMI. In addition, the frequency of abnormal chromosomal pairing was directly affected by the frequency of haploid production induced by parthenogenesis. The results of this study provide significant insights into the mechanism of parthenogenesis, which is probably due to the abnormal fertilization of synergid cells in alloplasmic $1 \mathrm{BL} / 1 \mathrm{RS}$ wheat.
\end{abstract}

Keywords: 1BL/1RS translocation, haploid frequency, male sterile line, Triticum aestivum, apomictic reproduction

Abbreviations: AC, antipodal cell; APAGE, acid polyacrylamide gel electrophoresis; EC, egg cell; MM, meiotic metaphase; PMC, pollen mother cell; PN, polar nuclei; SE, synergid embryo; SY, synergid

\section{Introduction}

Parthenogenesis involves a change from a gametophyte into a sporophyte without fertilization, which is known as fertilization-independent embryogenesis, and it leads to further development into haploid plants. In wheat, the alloplasmic line 'Salmon' with the

\footnotetext{
*Y.L. Song and N. Niu contributed equally to this work.

**Corresponding author; E-mail: zhanggsh58@aliyun.com
} 
$1 \mathrm{BL} / 1 \mathrm{RS}$ chromosome in its genome is a suitable material for parthenogenesis research (Barcaccia and Albertini 2013; Curtis and Grossniklaus 2008). It has been reported that the short arm of chromosome 1B from common wheat (Triticum aestivum L.) is substituted by the short arm of chromosome 1R from rye (Secale cereale L.) in 'Salmon', thereby yielding $1 \mathrm{BL} / 1 \mathrm{RS}$ translocation wheat. The transfer of the $1 \mathrm{BL} / 1 \mathrm{RS}$ nucleus into the cytoplasm of different Aegilops species can result in male sterile wheat lines (Ren et al. 2012; Zhou et al. 2013). Thus, Zhang et al. (1999) introduced the 1BL/1RS nucleus from wheat into the cytoplasm of different Aegilops species and successfully bred alloplasmic male sterile 1BL/1RS wheat lines with Ae. kotschyi, Ae. ventricosa, Ae. variabilis, and Ae. bicornis (Du et al. 2003). However, it was found that haploid plants were produced at specific frequencies by the different male sterile lines described above during hybrid wheat production (Wang et al. 2001). Indeed, it was confirmed that the production of haploid plants induced by Ae. kotschyi-'Salmon' was associated with an interaction between the 1BL/1RS translocation chromosome and the cytoplasm of Ae. kotschyi (Kobayashi and Tsunewaki 1980). In vitro culture of unfertilized egg cells (including synergids and central cells from the ovaries of alloplasmic wheat) suggests that the parthenogenesis of unfertilized egg cells is an inherent feature of alloplasmic 1BL/1RS wheat (Kumlehn et al. 2001). However, previous analyses of parthenogenesis by alloplasmic $1 \mathrm{BL} / 1 \mathrm{RS}$ wheat did not involve systematic cytogenetic and embryological investigations. In particular, the mechanism that allows different alloplasmic $1 \mathrm{BL} / 1 \mathrm{RS}$ wheat lines to produce haploids at various frequencies is unknown. Thus, to determine the effects of the $1 \mathrm{BL} / 1 \mathrm{RS}$ chromosome on parthenogenesis in different alloplasmic wheat lines, we assessed the 1RS chromosome and how the specific nuclear-alloplasm interaction impaired the pairing of homologous chromosomes in different alloplasmic 1BL/1RS wheat lines in order to obtain a theoretical understanding of the mechanism responsible for the different frequencies of haploids induced by alloplasmic 1BL/1RS wheat, as well as to facilitate further complementary cytogenetic and embryological research.

\section{Materials and Methods}

\section{Plant materials}

The alloplasmic 1BL/1RS wheat lines used in this experiment were Ae. kotschyi $-77(2)$, Ae. ventricosa -77(2), Ae. variabilis -77(2), Ae. kotschyi -Yanshi 9, Ae. ventricosa -Yanshi 9, Ae. variabilis -Yanshi 9, Ae. kotschyi-80(6), Ae. ventricosa-80(6), and Ae. variabilis -80(6), Ae. kotschyi -86-140, Ae. variabilis -86-140. The corresponding maintainer lines were T. aestivum -77(2), T. aestivum -Yanshi 9, and T. aestivum -80(6), and the restorer lines were T. aestivum -8869, T. aestivum -26-3, and T. aestivum -Xinong 9042, and two wheat lines T. aestivum -86-598, T. aestivum -86-536. All of the alloplasmic wheat lines were grown at the experimental station of Northwest A \& F University, China. The plants were bagged before the dehiscence of anthers and pollinated with the restorer lines at anthesis to obtain hybrid seeds ( $\mathrm{F}_{1}$ generation). We investigated different combinations to generate haploids and the haploid frequencies obtained with each combination. 


\section{Analysis of wheat root tips during mitosis}

Parents and their hybrids were germinated in a drainable Petri dish covered with sterilized filter paper in a $25{ }^{\circ} \mathrm{C}$ incubator until the roots measured 1-2 cm. Root tips (length = 1 $\mathrm{cm}$ ) were collected in glass vials and cold water at $9 \mathrm{am}$, and pre-treated for $22-24 \mathrm{~h}$ at $4{ }^{\circ} \mathrm{C}$. The root tips were then fixed in Carnoy's fluid containing ethanol:acetic acid $(3: 1)$ for 2-3 days at room temperature, stained with $1.5 \%$ fuchsin, and squashed in $45 \%$ acetic acid (Wu et al. 2006; Li et al. 2011). The best preparations were photographed using a Nikon Eclipse 600 microscope.

\section{Acid polyacrylamide gel electrophoresis (APAGE) analysis}

Gliadin was extracted from all of the materials, which was separated by APAGE (Shutov et al. 2012; Zi et al. 2012). Rye and 'Chinese Spring' wheat were used as controls.

\section{Cytological observation and investigation of haploid plants in the $F_{1}$ generation}

Young spikes from the $\mathrm{F}_{1}$ generation were fixed in freshly prepared Carnoy's fluid (ethanol:glacial acetic acid:chloroform $6: 3: 1$ by volume) before flowering and stained with $2 \%$ acetocarmine. The pollen mother cells (PMCs) were squashed to observe abnormal chromosomal pairing at meiotic metaphase I (MMI). The haploid plants were investigated mainly based on their morphological features as well as cytological analysis of the root tips using Feulgen stain.

\section{Microdissection of the embryo sac to observe unfertilized cells}

Some alloplasmic 1BL/1RS wheat plants were bagged before anthesis and then pollinated with rye pollen delaying about 7 days to obtain embryological observations. We harvested the female florets and isolated the ovaries, which were fixed in formalin:acetic acid:ethanol before anthesis, and observations were performed at 1, 2, 4, 6, 8, 10, 14, 16, 18, 20, 24, and $36 \mathrm{~h}$ after pollinating. The fixed embryo sacs were embedded and sliced to a thickness of about $12 \mu \mathrm{m}$, then staining with Ehrlich's hematoxylin and observing with an Olympus BH-2 microscope.

\section{Results}

Characteristics of chromosomes in the root tips of the parents and their hybrids

Chromosomes in the root tips of all materials were observed by microscopy in order to identify the properties of their 1B chromosomes. Two satellites were observed clearly in the male sterile lines and their maintainers, e.g., Ae. kotschyi-77(2) (Fig. 1a), and four satellites in the restorer lines, e.g., T. aestivum -Xinong 9042 (Fig. 1b). Three satellites were observed in the $\mathrm{F}_{1}$ obtained between Ae. kotschyi -77(2) and T. aestivum -Xinong 


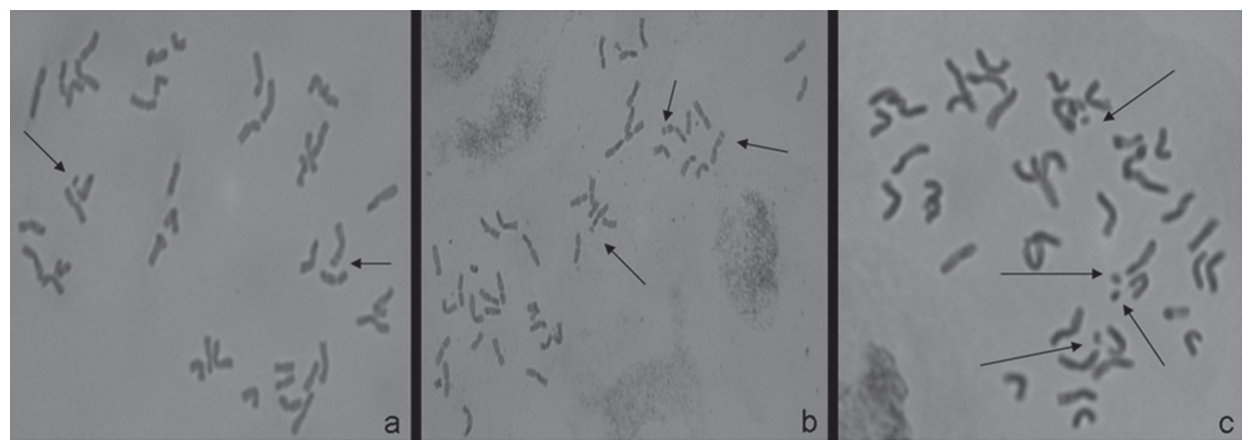

Figure 1. Characteristics of chromosomes in the root tips: (a) two satellites (arrow) in the root tip of Ae. kotschyi-77(2); (b) three satellites (arrow) in the hybrid between Ae. kotschyi -77(2) and T. aestivum -Xinong 9042; (c) four satellites (arrow) in T. aestivum -Xinong 9042

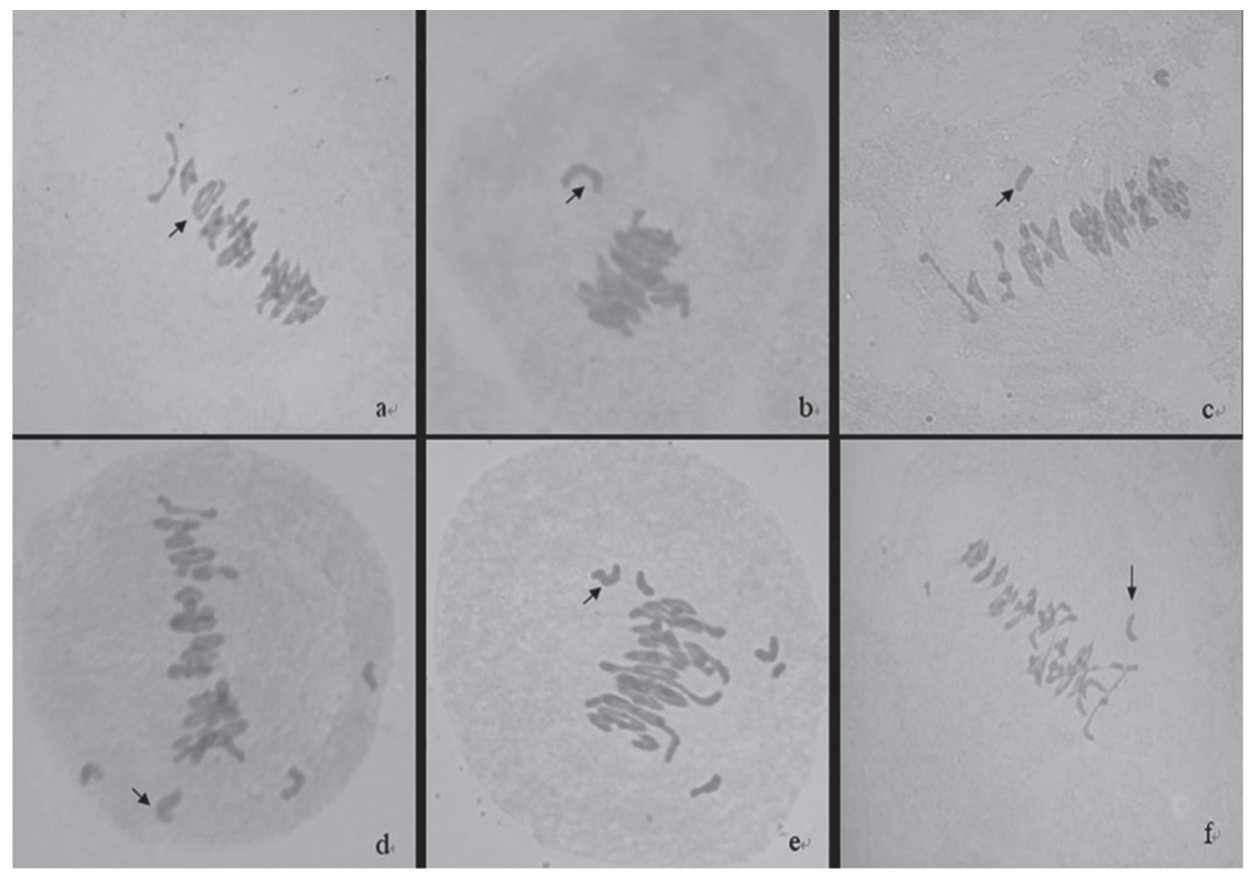

Figure 2. Homologous chromosome pairing at MMI in PMCs: (a) normal homologous chromosome pairing (arrow) at MMI in PMCs; (b-f) abnormal homologous chromosome pairing with 1-5 univalents (arrow) in the male sterile lines of alloplasmic $1 \mathrm{BL} / 1 \mathrm{RS}$ wheat lines and the $\mathrm{F}_{1}$ after crossing with non-1BL/1RS restoration lines, respectively, at MMI in PMCs 
Table 1. Frequencies of abnormal cells in alloplasmic 1BL/1RS wheat lines and their maintainers

\begin{tabular}{|c|c|c|c|c|}
\hline Materials & $\begin{array}{c}\text { Numbers of cells } \\
\text { observed }\end{array}$ & $\begin{array}{c}\text { Numbers of } \\
\text { abnormal cells at } \\
\text { MMI }\end{array}$ & $\begin{array}{c}\text { Frequency of } \\
\text { abnormal cells at } \\
\text { MMI }(\%)\end{array}$ & $t$ value \\
\hline T. aestivum $-77(2)$ & 259 & 25 & 9.65 & - \\
\hline Ae. kotschyi $-77(2)$ & 132 & 31 & 23.48 & $3.68 * *$ \\
\hline Ae. ventricosa $-77(2)$ & 232 & 39 & 16.81 & $2.31 *$ \\
\hline Ae. variabilis $-77(2)$ & 289 & 63 & 21.80 & $3.85 * *$ \\
\hline T. aestivum -Yanshi 9 & 54 & 5 & 9.26 & - \\
\hline Ae. kotschyi -Yanshi 9 & 202 & 20 & 9.90 & 0.14 \\
\hline Ae. ventricosa-Yanshi 9 & 329 & 30 & 9.12 & 0.02 \\
\hline Ae. variabilis -Yanshi 9 & 138 & 20 & 14.50 & 1.01 \\
\hline T. aestivum $-80(6)$ & 47 & 4 & 8.51 & - \\
\hline Ae. kotschyi $-80(6)$ & 128 & 15 & 11.72 & 0.33 \\
\hline Ae. variabilis $-80(6)$ & 238 & 48 & 20.17 & 1.69 \\
\hline
\end{tabular}

** Significant difference at $P<0.01$; * Significant difference at $P<0.05$.

9042 (Fig. 1c). These results indicate that all of the male sterile lines and their maintainers contained 1BL/1RS chromosome in their genomes, and they were 1BL/1RS translocation lines, whereas the restorer lines lacked the 1BL/1RS chromosome.

\section{APAGE analysis}

Electrophoresis of gliadins indicated that all of the male sterile lines possessed the gliadin marker Gli-B3 of the 1BL/1RS translocation chromosome (Fig. S1*, lanes 3-11) and the results for all of the maintainer lines were the same as those for the male sterile lines. All of the restorers lacked the Gli-B3 marker of the 1BL/1RS translocation chromosome (lanes 12-14).

\section{MMI analysis of the different hybrid combinations}

The frequency of abnormal cells (i.e. cells with frequent abnormal chromosomal pairing at MMI) at MMI differed slightly or greatly among the alloplasmic 1BL/1RS wheat lines, but abnormal homologous chromosome pairing (Fig. 2) occurred in all hexaploid wheat lines with both euplasm and alloplasm (Table 1).

The frequency of abnormal cells at MMI was significantly higher in karyotype 77(2) for the three alloplasms compared with that in the euplasm. However, the karyotypes Yanshi 9 and 80(6) for the alloplasms had lower frequencies of abnormal cells compared with that in the euplasm at MMI. It is possible that the size of the $1 \mathrm{R}$ chromosome translocated from rye varied among karyotypes 77(2), Yanshi 9, and 80(6), which is consistent

\footnotetext{
* Further details about the Electronic Supplementary Material (ESM) can be found at the end of the article.
} 
Table 2. Differences in the haploid frequency for three isonuclear alloplasmic 1BL/1RS wheat lines

\begin{tabular}{|l|c|c|c|c|c|c|c|}
\hline \multicolumn{1}{|c|}{ Materials } & \multirow{2}{*}{$\begin{array}{c}\text { Totle number } \\
\text { of } \\
\text { combinations }\end{array}$} & $\begin{array}{c}\text { No. of } \\
\text { combinations } \\
\text { of haploids }\end{array}$ & $\begin{array}{c}\text { No. of plants } \\
\text { for each } \\
\text { combination }\end{array}$ & $\begin{array}{c}\text { S.D. among } \\
\text { combinations } \\
\text { of haploid }\end{array}$ & \multicolumn{2}{|c|}{$\begin{array}{c}\text { Average } \\
\text { haploid } \\
\text { frequency }\end{array}$} & \multicolumn{2}{|c|}{$\begin{array}{c}\text { Significance of } \\
\text { difference }\end{array}$} \\
\hline $\begin{array}{l}\text { Ae. kotschyi } \\
\text {-Yanshi 9 }\end{array}$ & 15 & 11 & 60 & 10.75 & 18.25 & $\mathrm{a}$ & $\mathrm{A}$ \\
\hline $\begin{array}{l}\text { Ae. ventricosa } \\
\text {-Yanshi 9 }\end{array}$ & 15 & 3 & 60 & 7.69 & 12.64 & $\mathrm{a}$ & $\mathrm{A}$ \\
\hline $\begin{array}{l}\text { Ae. variabilis } \\
\text {-Yanshi 9 }\end{array}$ & 15 & 12 & 60 & 11.14 & 18.20 & $\mathrm{a}$ & $\mathrm{A}$ \\
\hline
\end{tabular}

with the results reported by Wang et al. (1999), which showed that the size of the fragment of the rye $1 \mathrm{R}$ chromosome translocated into wheat varied slightly, thereby affecting homologous chromosomal pairing.

The haploid frequency in the $\mathrm{F}_{1}$ generation using the same nucleus but different alloplasm types did not differ significantly (Table 2), which suggests that the nucleus plays a major role in inducing haploid plants and different alloplasm types may affect haploid production to various extents.

The reaction to the nucleus in these alloplasm types was very similar with the same $1 \mathrm{BL} / 1 \mathrm{RS}$ nucleus, which suggests that haploid induction was affected by the cytoplasm in these alloplasmic 1BL/1RS wheat lines.

We determined the correlations between the frequency of abnormal cells at MMI and the haploid frequency (Table 3). There were significant correlation in the male parents hybridized with the three alloplasmic 1BL/1RS wheat lines, i.e., 0.9542, 0.8763, and 0.9990. Unlike the other two male parents, and T. aestivum -Xinong 9042 could hybridize with the three alloplasmic 1BL/1RS wheat lines to induce haploid plants, but T. aestivum -8869 and T. aestivum -26-3 hybridized with Ae. ventricosa -Yanshi 9 could not. Presumably, this alloplasmic 1BL/1RS wheat line (Ae. ventricosa-Yanshi 9) requires specific pollen donors to induce haploids.

We also observed that the spikes bagged before the flowering of male sterile lines of alloplasmic 1BL/1RS wheat did not induce haploid plants without pollination or stimulation with any pollen in this study.

Table 3. Comparison of the frequency of abnormal cells and haploid frequency in hybrid combinations

\begin{tabular}{|l|c|c|c|c|}
\hline \multirow{2}{*}{ Material } & \multirow{2}{*}{$\begin{array}{c}\text { Frequency } \\
\text { of abnormal cells } \\
\text { at MMI (\%) }\end{array}$} & \multicolumn{2}{|c|}{ Haploid frequency of the three hybrid combinations (\%) } \\
\cline { 3 - 5 } & 9.92 & 12.00 & 11.76 & 9042 \\
\hline Ae. kotschyi -Yanshi 9 & 9.17 & 0.00 & 20.83 & 5.80 \\
\hline Ae. ventricosa -Yanshi 9 & 14.24 & 28.00 & 36.84 & 0.00 \\
\hline Ae. variabilis -Yanshi 9 & - & 0.9542 & 0.8763 & 30.00 \\
\hline Correlation coefficient & - & & T. aestivum -Xinong $-26-3$ \\
\hline
\end{tabular}




\section{Microdissection of the embryo sacs of the alloplasmic 1BL/1RS wheat}

The ovaries of alloplasmic 1BL/1RS wheat lines were analyzed before pollination to observe their developmental condition and the results showed that most of the ovaries were developing normally.

The egg cells located near the ovule pore contained cytosol and small vacuoles, and the nucleus was present in the center (Fig. 3a), while the synergids and egg cells were arranged in a triangular configuration (Fig. 3b). The two polar nuclei were close together in the center of the embryo sac. However, in some individuals, the deficiency of nutrients due to delayed pollination caused the disassembly of antipodal cells and the disappearance of other components of the embryo sac (Fig. 3c). Normal fertilization was observed after pollination. In general, the optimum period for the pollination of alloplasmic $1 \mathrm{Bl} / 1 \mathrm{RS}$ wheat is at anthesis. The stigma begins to age after 7 days, which may reduce the capacity for successful double fertilization, and the cells finally degenerate without pollination (Fig. 3f). Our experiment showed that $1 \mathrm{RS}$ elongated the period available for

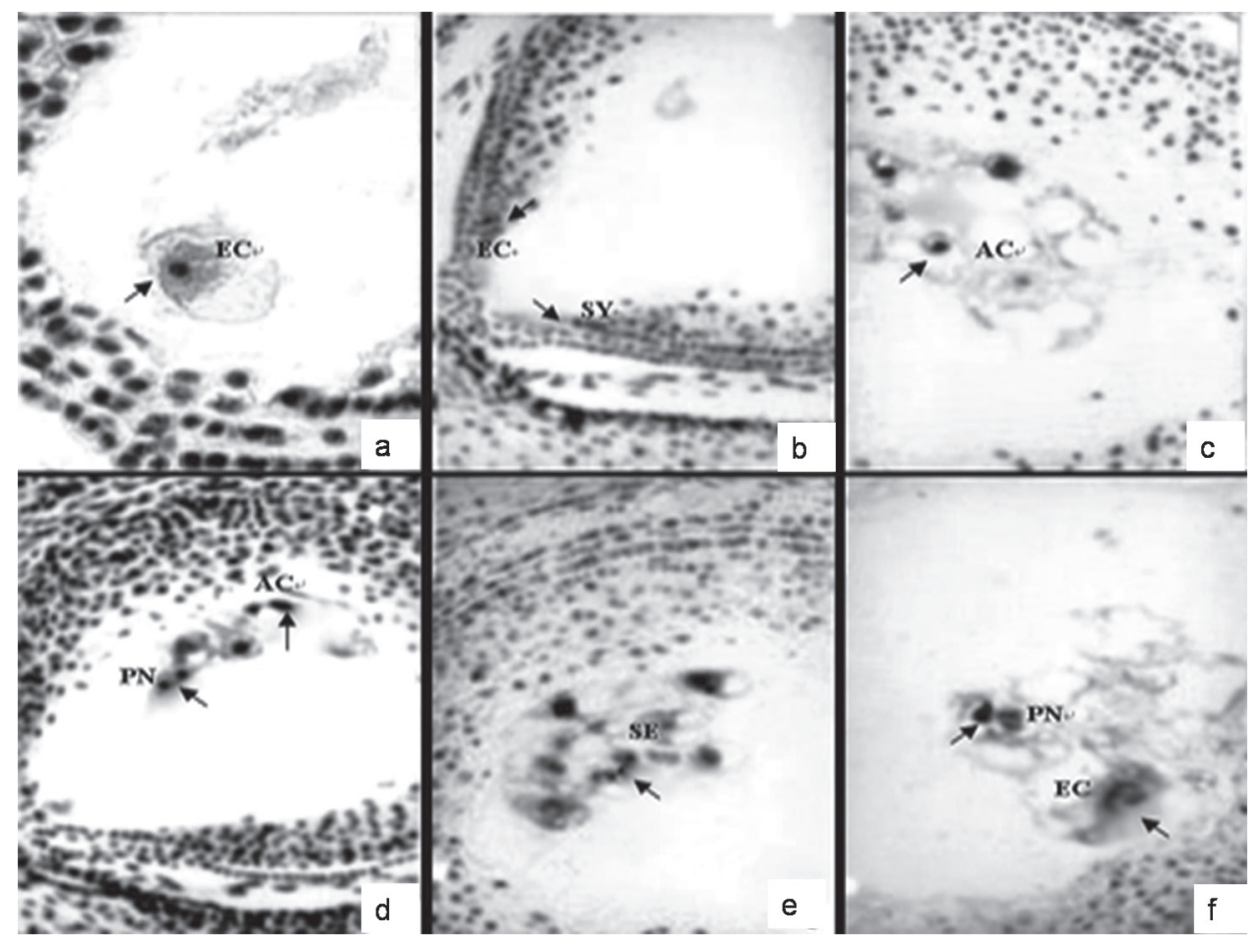

Figure 3. Developmental condition of the embryo sac in an alloplasmic 1BL/1RS wheat line: (a) egg cell (EC arrow) before delayed pollination; (b) triangle-shaped egg cell (EC arrow) and synergid (SY arrow) before delayed pollination; (c) disassembling antipodal cell (AC arrow) before delayed pollination; (d) unfertilized polar nuclei (PN) close to the antipodal cells at $10 \mathrm{~h}$ after pollination; (e) synergid embryo (SE arrow) near the integument at $3 \mathrm{~h}$ after pollination; (f), egg cell (EC arrow) beginning to divide at $36 \mathrm{~h}$ after pollination 
pollination and strengthened the capacity of the stigma for pollen acceptance. Abnormal fertilization was also observed (Fig. 3d-e). This suggests that parthenogenesis may be related to synergids in the embryo sac in some alloplasmic 1BL/1RS wheat lines.

\section{The haploid induced by parthenogenesis, not by etheogenesis}

In addition, we observed $n-2 n$ and $n-n$ twin plants from male sterile lines of alloplasmic $1 \mathrm{Bl} / 1 \mathrm{RS}$ wheat and its $\mathrm{F}_{1}$ in this experiment (Fig. S2).

The male sterile lines were substituted and a marker genotype, awnedness, was used in the study (Table S1). When the awned sterile lines were crossed with the awnless male parent, the $n$ plants were all awnless but the $2 n$ plants were all awnless, and the $n-n$ twin plants plants were all awned in $\mathrm{F}_{1}$. Whereas the awnless sterile lines were crossed with the awned male parent, the $2 \mathrm{n}$ and the $\mathrm{n}$ plants were all awned in all kinds of plants in $\mathrm{F}_{1}$, and these awnless $2 \mathrm{n} \mathrm{F}_{1}$ plants backcrossed with awnless male parents, the $n-n$ twin plants of $\mathrm{BC}_{1}$ were either awned or awnless. These results demonstrated the fertilization of the synergid nuclei or the synergid nuclei and egg nuclei, and then development of haploid embryos. In addition, this study also showed that the haploid was parthenocarpic in twin plants.

\section{Discussion}

According to our experimental results, we conclude that the size of the $1 \mathrm{BL} / 1 \mathrm{RS}$ chromosome and the nucleo-alloplasm interaction both affected the pairing of homologous chromosomes, where the interaction between the 1BL/1RS chromosome and the alloplasm weakened the pairing of homologous chromosomes. It is possible that the cytogenetic mechanism of parthenogenesis induced by the $1 \mathrm{BL} / 1 \mathrm{RS}$ male sterile lines or the $\mathrm{F}_{1}$ is directly related to the frequency of haploid plant production in wheat.

In alloplasmic hexaploid wheat, other studies also indicate that haploid production is controlled by the concurrent absence of $1 \mathrm{BS}$ and the presence of 1RS. The wheat cultivar 'Amigo' with a complete 1B wheat chromosome pair and a 1AL/1RS translocation chromosome was crossed with another wheat line that possessed a complete 1B chromosome pairing and translocated 1DL/1RS chromosome, and then backcrossed into (Ae. kotschyi)'Salmon' without haploid production (Shepherd 1973). This phenomenon demonstrates that haploid induction is not possible in the presence of both 1BS and 1RS. However, haploids can be induced in alloplasmic 1BL/1RS wheat. This evidence confirms that haploid induction is due to the interaction between the 1BL/1RS nucleus and specific alloplasm types in hexaploid wheat, which was also shown in tetraploid wheat (Dunwell 2010). William et al. (2003) confirmed that 'Salmon' system lines pollinated by maize (Zea mays L.) pollen generally had higher embryo formation and haploid formation frequencies compared with those that possessed a genotype without 1BL/1RS translocation. Furthermore, it not known whether alloplasmic wheat lacking the 1BS chromosome but with the $1 \mathrm{RS}$ chromosome, such as the $1 \mathrm{BL} / 1 \mathrm{VS} \cdot 1 \mathrm{AL} / 1 \mathrm{RS}$ genotype, which has $1 \mathrm{~V}$ from 
Dasypyrum villosum, would produce haploid plants in its $\mathrm{F}_{1}$ hybrid generation and this may be of further importance for widespread haploid breeding in wheat.

In addition, the mechanism of haploid production has been studied extensively in crosses using morphological markers and aneuploid lines in the alloplasmic 1BL/1RS wheat 'Salmon' system (Berzonsky et al. 2003). It was demonstrated that two nuclear genes are responsible for the initiation of autonomous embryos in addition to the cytoplasmic factor, i.e., a parthenogenesis-inducing gene (Ptg) located on the 1RS segment, which is regulated in the sporophyte, and a parthenogenesis-suppressing gene (Psg) located on the $1 \mathrm{~B}$ short chromosome arm, which is controlled in the gametophyte. Kumlehn et al. (2001) constructed egg cell-specific cDNA libraries to screen parthenogenesis-related genes in 1BL/1RS wheat. However, there have been no previous reports for genes other than Ptg or Psg. Our study indicated that haploid plants can be induced in three alloplasmic 1BL/1RS wheat lines due to the interaction between Aegilops cytoplasm and 1BL/1RS chromosomal translocation, which may directly impair the capacity for homologous chromosome pairing, as described by Zhang et al. (1999), and this is consistent with $p t g$ expression during gamete development.

Our embryological observations suggested that delayed pollination in alloplasmic $1 \mathrm{BL} / 1 \mathrm{RS}$ wheat could increase haploid production due to the recession of egg cells and the continuous development of synergids. This result was also obtained in wheat with Ae. kotschyi cytoplasm (Sun et al. 1994). Another study showed that apomixis was affected by abnormal chromosome pairing during meiosis because premature egg cell division was caused by the 1BL/1RS chromosome (Liu et al. 2003). Yao et al. (1994) confirmed that apomixis can arise from both egg cells and synergids in the unfertilized embryo sac in rice (Yao et al. 1994; Tian et al. 2013). Thus, it is likely that the egg-like synergid in unfertilized embryos could develop into haploid plants. In this study, the awnedness of the $\mathrm{F}_{1}$ is clearly the key to explaining the results of $\mathrm{BC}_{1}$ performance. In general, based on the knowledge of the female gamete forming, regardless of whether its nucleus genotype is hetero or pure, the macrosporocyte $(2 n)$ forms four macrospores (n) after meiosis. Three of these four macrospores disintegrate and the remaining macrospore develops eight nuclei via three rounds of mitosis in the embryo sac. Each nucleus in the embryo sac, i.e., the egg and synergid nuclei, has the same genotype. Thus awnedness segregation does not occur in the same n-n twin plants under parthenogenesis. So there is also a probability of etheogenesis besides. Where awnless sperm nuclei and awned egg nuclei might develop in an n-n twin plant, and the n-n twin plant may be segregated by awnedness when using awned material as female and awnless material as male parent in a backcross. But, if the haploid plant is completely induced by male parthenogenesis, there would be no awned n-n twin plants in $\mathrm{F}_{1}$ and $\mathrm{BC}_{1}$. In fact, the awned $\mathrm{n}-\mathrm{n}$ twin plants were found in the $\mathrm{F}_{1}$ and $\mathrm{BC}_{1}$, but no $\mathrm{n}$ - $\mathrm{n}$ twin plants segregated for awnedness in $\mathrm{BC}_{1}$. These facts support our hypothesis that the haploid plants obtained in this study were induced by female parthenogenesis, and not by male parthenogenesis. This hypothesis regarding the origin of parthenocarpic cells requires further confirmation in embryos using in situ hybridization at the molecular cell level where sufficient molecular markers should be selected in key chromosomes. 


\section{Acknowledgements}

The research was supported by the National High Technology Research and Development Program of China (No. 2011AA10A106), National Natural Science Foundation of China (Nos. 31171611 and 31371697), The Key Scientific and Technological Innovation Special Projects of Shaanxi (2014KTZB02-01-02), the Fundamental Research Funds for the Central Universities (2452013QN110), Natural Science Foundation of Shaanxi Province (2015JQ3086), Cyrus Tang Foundation of North West A\&F University and the National Support Program of China (2015BA027801).

\section{References}

Barcaccia, G., Albertini, E. 2013. Apomixis in plant reproduction: a novel perspective on an old dilemma. Plant Reprod. 26:159-179.

Berzonsky, W.A., Kleven, S.L., Leach, G.D. 2003. The effects of parthenogenesis on wheat embryo formation and haploid production with and without maize pollination. Euphytica 133:285-290.

Curtis, M.D., Grossniklaus, U. 2008. Molecular control of autonomous embryo and endosperm development. Sex. Plant Reprod. 21:79-88.

Du, W.L., Zhang, G.S., Liu, H.W., Wang, J.W., Wang, X.L., Zhao, Z.J. 2003. Studies on fertility restoration performance of male sterile lines of non-1BL/1RS wheat with Ae. kotschyi, Ae. variabilis and Ae. ventricosa cytoplasms. Acta Bot. Boreal.-Occident. Sin. 23:69-74. (in Chinese with English abstract)

Dunwell, J.M. 2010. Haploids in flowering plants: origins and exploitation. Plant Biotechnol. J. 8:377-424.

Kobayashi, M., Tsunewaki, K. 1980. Haploid induction and its genetic mechanism in alloplasmic common wheat. Hereditas 71: 9-14.

Kumlehn, J., Kirik, V., Czihal, A., Altschmied, L., Matzk, F., Lörz, H., Bäumlein, H. 2001. Parthenogenetic egg cells of wheat: cellular and molecular studies. Sex. Plant Reprod. 14:239-243.

Li, X.J., Hu, T.Z., Li, G., Dong, N., Feng, S.W., Jiang, X.L., Ru, Z.G. 2011. A method to observe chromosomes with wheat stem tip meristem. J. of Henan Agric. Sci. 40:18-20. (in Chinese with English abstract)

Liu, H.M., Zhang, G.S., Liu, H.W., Wang, J.W., Yao, Y.Q. 2003. Primary studies on the mechanism of parthenogenesis induced by $1 \mathrm{BL} / 1 \mathrm{RS}$ male sterile line with Ae. ventricosa cytoplasm in wheat. Acta Bot. Boreal.Occident. Sin. 23:1772-1775. (in Chinese with English abstract)

Ren, T.H., Chen, F., Yan, B.J., Zhang, H.Q., Ren, Z.L. 2012. Genetic diversity of wheat-rye 1BL/1RS translocation lines derived from different wheat and rye sources. Euphytica 183:133-146.

Shepherd, K.W. 1973. Homoeology of wheat and alien chromosomes controlling endosperm protein phenotypes. In: Sears, E.R., Sears, L.M.S. (eds), Proc. 4th Int. Wheat Genetics Symp. Columbia, Missouri, USA. pp. 745-760.

Shutov, A., Rudakova, A., Rudakov, S., Kakhovskaya, I., Schallau, A., Maruyama, N., Wilson, K. 2012. Limited proteolysis regulates massive degradation of glycinin, storage $11 \mathrm{~S}$ globulin from soybean seeds: An in vitro model. J. Plant Physiol. 169:1227-1233.

Sun, S.Y., Yang, T.Z., Liu, W.G. 1994. Studies on the cytology of the synergid apogamny by Ae. kotschyi cytoplasm male sterile in common wheat. Acta Univ. Agric. Boreal.-Occident. 22:29-34. (in Chinese with English abstract)

Tian, Z.X., Ma, H.L., Zhang, Y.M. 2013. Embryo types and characteristics of apomixis in Poa pratensis L. Sci. Agric. Sin. 46:2633-2642. (in Chinese with English abstract)

Wang, X.L., Zhang, G.S., Liu, H.W., Wang, J.W. 1999. Studies on cytologic characteristic of several male sterile lines of alloplasmic 1B/1R wheat. Acta Botanica Boreali-Occidentalia Sinica 19:642-647. (in Chinese with English abstract)

Wang, X.L., Zhang, G.S., Liu, H.W., Wang, J.W. 2001. Cytogenetic studies on parthenogenesis of 1B/1R wheat male sterile lines. Acta Agric. Boreal.-Occident. 10:56-59. (in Chinese with English abstract) 
William, A., Berzonsky, S., Kleven, L., Leach, D. 2003. The effect of parthenogenesis on wheat embryo formation and haploid production with and without maize pollination. Euphytica 133:285-290.

Wu, J., Yang, X.M., Wang, H., Li, H.J., Li, L.H., Li, X.Q., Liu, W.H. 2006. The introgression of chromosome 6P specifying for increased numbers of florets and kernels from Agropyron cristatum into wheat. Theor. Appl. Genet. 114:13-20.

Yao, J.L., Cai, D.T., Ma, P.F., Wang, Z.A., Zhu, H. 1994. The embryological studies on HDAR002 of apomixes rice. J. Huazhong Agric. Univ. 13:339-343.

Zhang, G.S., Ma, S.M., Wang, X.L., Liu, H.W., Wang, J.W., Zhao, H.Y. 1999. Studies on inducing parthenogenesis of some male sterile lines of alloplasmic 1BL/1RS wheat. Acta Bot. Boreal.-Occident. Sin. 19:1-9. (in Chinese with English abstract)

Zhou, J.W., Han, C.X., Cao, H., Zhen, S.M., Yu, Z.T., Li, X.H., Ma, W.J., Yan, Y.M. 2013. Fast identification of wheat 1BL/1RS translocation by reversed-phase ultra-performance liquid chromatography (RP-UPLC). Crop Pasture Sci. 64:865-873.

Zi, J., Zhang, J.Y., Wang, Q.H., Lin, L., Tong, W., Bai, X., Zhao, J.J., Chen, Z., Fu, X.Q., Liu, S.Q. 2012. Proteomics study of rice embryogenesis: Discovery of the embryogenesis dependent globulins. Electrophoresis 33:1129-1138.

\section{Electronic Supplementary Material (ESM)}

Electronic Supplementary Material (ESM) associated with this article can be found at the website of CRC at http://www.akademiai.com/content/120427/

Electronic Supplementary Table S1. Genetic analysis of $\mathrm{F}_{1}$ and $\mathrm{BC}_{1}$ between two alloplasmic wheat male sterile lines and two wheat lines with different awnedness

Electronic Supplementary Figure S1. APAGE analysis of gliadin in all the male sterile lines and restorer lines. Lanes 1 to 14 represent: Chinese Spring, rye, Ae. kotschyi-77(2), Ae. ventricosa -77(2), Ae. variabilis -77(2), Ae. kotschyi -Yanshi 9, Ae. ventricosa -Yanshi 9, Ae. variabilis -Yanshi 9, Ae. kotschyi -80(6), Ae. ventricosa -80(6), Ae. variabilis -80(6), T. aestivum -8869, T. aestivum -26-3, T. aestivum -Xinong 9042

Electronic Supplementary Figure S2. Seedling morphology in n-2n and n-n twin plants from male sterile lines of alloplasmic $1 \mathrm{BL} / 1 \mathrm{RS}$ wheat and $\mathrm{F}_{1}$.

(a) haploid (right) and diploid (left) seedlings; (b) n-2n twin seedling; (c) n-n twin seedling 